\title{
Patterns of diabetes care in Slovenia, Croatia, Serbia, Bulgaria and Romania
}

\section{An observational, non-interventional, cross-sectional study}

\author{
Miro Cokolic (D) - Nebojsa M Lalic · Dragan Micic · Gorana Mirosevic · Sanja Klobucar Majanovic • \\ Ivaylo N Lefterov · Mariana Graur
}

Received: 7 April 2016 / Accepted: 12 November 2016 / Published online: 8 December 2016

(C) The Author(s) 2016. This article is available at SpringerLink with Open Access.

\begin{abstract}
Summary
Background National guidelines for treating type 2 diabetes in the Balkans generally follow European guidelines. The current study was undertaken to estimate the rate of glycated hemoglobin (HbAlc) measurements and level of HbAlc control in diabetic patients treated in regular clinical practice settings in the Balkans and to evaluate if providing HbAlc measurements improves adherence to treatment guidelines.

Methods This cross-sectional study enrolled type 2 diabetic patients treated by 79 primary care physicians and 102 specialists. The participants were provided with HbAlc measuring devices to measure HbAlc during regular office visits and a physician survey evaluated HbAlc the results feedback. Relevant clinical, demographic, drug treatment and specialist referral data were extracted from patient charts.
\end{abstract}

\section{Author's contributions All authors were involved in the interpretation of the analyses. All authors were involved in critical revision of the manuscript for important intellectual content. All authors approved the final manuscript.}

\section{Prim. Assist. M. Cokolic, M.D. ( $\square)$}

Department for Endocrinology and Diabetes, University

Medical Center Maribor, Ljubljanska ulica 5, 2000 Maribor, Slovenia

miro.cokolic@ukc-mb.si

N. M. Lalic · D. Micic

Clinic for Endocrinology, Diabetes and Metabolic Diseases, Clinical Center of Serbia, Belgrade, Serbia

\section{N. M. Lalic}

lalicnm@gmail.com

D. Micic

micicd@eunet.rs
Descriptive statistics and stepwise multivariate regression analysis were used.

Results Among 1853 patients included (average age $63.5 \pm 10.7$ years, $51 \%$ male) the average diabetes duration was $8.9 \pm 7.1$ years, $40 \%$ of patients had HbAlc measured every 6 months and $34 \%$ every 12 months (or less frequently). The rate of 6-month measurement was higher among specialists (43\%) vs. primary care physicians $(32 \%, p<0.01)$. The average HbAlc was $7.3 \pm 1.5$ and $35 \%$ of patients achieved the target HbAlc level of $<6.5 \%$. Metformin monotherapy was prescribed to $28 \%$ of patients and metformin + sulphonylurea to $23 \%$, $55 \%$ of patients on metformin monotherapy and $32 \%$ of patients on dual therapy metformin + sulphonylurea achieved the target HbAlc $<6.5 \%$. Treatment remained unchanged in $91 \%$ and was stepped up in only $7.2 \%$ of patients. Physicians were not surprised (in $79 \%$ of patients) or were pleasantly surprised (in $11 \%$ ) by the HbAlc

\section{G. Mirosevic}

Department of Endocrinology, Diabetes and Metabolic

Diseases "Mladen Sekso", Clinical Hospital Centre "Sisters of Mercy", Zagreb, Croatia

goranamirosevic1@net.hr

\section{S. Klobucar Majanovic}

Department of Internal Medicine, Division of

Endocrinology, Diabetes and Metabolic Disorders,

University Hospital Rijeka, Rijeka, Croatia

sanja.klobucarm@gmail.com

\section{N. Lefterov}

Diagnostic Consultative Center XII, Sofia, Bulgaria ilefterov@dir.bg

M. Graur

Grigore T. Popa University of Medicine and Pharmacy, Iasi, Romania

graur.mariana@gmail.com 
Table 1 Study flow chart

\begin{tabular}{|l|l|}
\hline $\begin{array}{l}\text { Planning and obtaining approval from authorities } \\
\text { (ethical and regulatory agency approval) }\end{array}$ & $\begin{array}{l}\text { Approximate dura- } \\
\text { tion in months }\end{array}$ \\
\hline $\begin{array}{l}\text { Investigators meeting, training for doctors involved in } \\
\text { study procedures, including the use of measurement } \\
\text { devices }\end{array}$ & 2 \\
\hline $\begin{array}{l}\text { Recruiting patients, obtaining informed consent and } \\
\text { collecting data }\end{array}$ & 1 \\
\hline $\begin{array}{l}\text { Collecting of case report forms (CRF) } \\
\text { Data analysis }\end{array}$ & 1 \\
\hline
\end{tabular}

results at the time of visit. Average diabetes duration and patient use of home glucometers were associated with the level of disease control.

Conclusions The rates of HbAlc measurements remain low in the Balkans, although higher among specialists. Over $60 \%$ of patients, mostly treated with traditional oral antidiabetics did not achieve disease control. Providing convenient HbAlc measurement devices was not associated with a marked change in diabetes management. Future research is needed to evaluate the impact of these treatment patterns on long-term outcomes and costs to society.

Keywords Type 2 diabetes - Clinical practice $\cdot$ HbAlc measurement rate - Glycemic control · Diabetes therapy

\section{Introduction}

Diabetes mellitus (DM) is a chronic disease that requires continuous medical care and patient selfmanagement, education and support in order to prevent acute complications and reduce the risk of longterm complications. It is considered one of the greatest health challenges of the twenty-first century. In 2013 DM caused 5.1 million deaths [1] and a person dies from diabetes every $6 \mathrm{~s}$ [1]. According to the International Diabetes Federation (IDF), 8.3\% of adults have diabetes, and the number of people living with diabetes is expected to rise from 382 million in 2013 to 592 million in less than 25 years [1]. Type 2 DM accounts for $90 \%$ of all diabetes cases [2]. The 2006 World Health Organization (WHO) diagnostic criteria for diabetes are fasting plasma glucose $\geq 7.0 \mathrm{mmol} / \mathrm{l}(126 \mathrm{mg} / \mathrm{dl})$ or 2 -h plasma glucose $\geq 11.1 \mathrm{mmol} / \mathrm{l}(200 \mathrm{mg} / \mathrm{dl})$ [3]. In 2009, an international expert committee including representatives of the American Diabetes Association (ADA), the IDF and the European Association for the Study of Diabetes (EASD) recommended the use of the HbAlc test to diagnose diabetes, with a threshold of $\geq 6.5 \%$ ( $48 \mathrm{mmol} / \mathrm{mol}$ ) and the ADA adopted this criterion in 2010. Furthermore, the two most influential largescale clinical trials of diabetes therapeutic regimens, the Diabetes Control and Complications Trial (DCCT) and the United Kingdom Prospective Diabetes Study
(UKPDS), have shown that improving HbAlc levels slows the development and progression of eye, kidney, and nerve complications in both type 1 and type $2 \mathrm{DM}$ [4-6]. There are two primary techniques available to assess the effectiveness of the glycemic control management plan: blood glucose and HbAlc monitoring [7]. The most abundant minor hemoglobin component is HbAlc and it is formed by the chemical condensation of hemoglobin and glucose [6, 8]. Glycated hemoglobin is measured primarily to identify average plasma glucose concentrations over prolonged periods of time and HbAlc has a strong predictive value for diabetes complications [9-12]. The target HbAlc level is $<6.5 \%(48 \mathrm{mmol} / \mathrm{mol})$ and this concentration is recommended as a diagnostic indicator of disease control and the effectiveness of therapy. The test should be repeated every 3 months until the target value is reached, and every 6 months thereafter [13-17]. If dietary treatment for DM is not effective, then pharmacological treatment is usually initiated. Unless contraindicated, metformin is recommended as a first line therapy in addition to diet and exercise.

National guidelines for treating DM in the Balkans generally follow European guidelines; however, the rate of routine $\mathrm{HbAlc}$ measurements in type $2 \mathrm{DM}$ patient care among practitioners in the Balkans is uncertain. The current study was undertaken to estimate the rate of $\mathrm{HbAlc}$ measurement and the level of disease control in patients with type $2 \mathrm{DM}$ in the Balkans, and to evaluate if providing a cost free and simple way to measure HbAlc levels leads to the more aggressive treatment of patients who have poor disease control. The primary objective of this study was to determine the rate of HbAlc testing in patients with type 2 DM among general practitioners (GPs) and diabetes specialists, and to estimate adherence to treatment guidelines. The secondary objective was to establish whether HbAlc testing improves adherence to treatment guidelines.

\section{Patients, materials and methods}

The study was performed as a multicenter study in the Balkan countries, represented by Croatia, Slovenia, Serbia, Romania, and Bulgaria. This study was performed as an observational, non-interventional, and cross-sectional study. It was performed over 3-month periods, in 2013 and the beginning of 2014 (Table 1, available online).

\section{HbA1c measurement}

Physicians were provided with HbAlc measuring devices (Siemens, Erlangen, Germany) for the purpose of the study [18]. 


\section{Diagnostic criteria}

Diabetes was defined according to the 2006 WHO diagnostic criteria as fasting plasma glucose $\geq 7.0 \mathrm{mmol} / \mathrm{l}$ $(126 \mathrm{mg} / \mathrm{dl})$ or $2-\mathrm{h}$ plasma glucose $\geq 11.1 \mathrm{mmol} / \mathrm{l}$ (200 mg/dl) [3].

\section{Physicians}

The participating physicians represented different regions of the Balkan countries. The target was to enrol equal numbers of general practitioners and specialists in each country, except in Romania, where only specialists were enrolled due to the fact that patients with type 2 diabetes are treated only by internists/ diabetologists. A total of 181 physicians participated in this study of whom 79 were GP/general medical specialists and 102 were internists/diabetologists. All participating physicians attended several training meetings and were certified before recruitment. The physicians were divided into three groups according to HbAlc measurement frequency. At the end of the study, physicians were asked to provide feedback as to whether the HbAlc level results of their patients were as expected, better than expected, or worse than expected.

\section{Patients}

Eligible patients with type 2 DM were adults ( $\geq 18$ years of age) treated with oral antihyperglycemic agents or insulin at least 6 months before enrollment. A total of 1853 patients were enrolled, 479 patients treated by GP and 1331 regularly seen by diabetes specialists. The patients were recruited during regular office visits after signing an informed consent form. The population living in the study area was genetically a relatively uniformly Caucasian population, and no different ethnic groups were expected to be living there. The total population of the Balkans is 59 million of whom 34 million are adults between 27 and 69 years of age. Bearing in mind that the average prevalence of diabetes in the region was $7.6 \%$ in 2013 according to the IDF, the rough estimate is that there were approximately 3 million adults with diabetes in the region at the time the study was conducted [1]. Patient history data were taken along with HbAlc measurements. Fingerprick testing of HbAlc was performed on site [18]. Diabetes therapy on the visit date and any change in therapy on the same date, possible referral to a specialist, prior medication history, and records of prior medication taken by the subject within the past 6 months before the study were all noted.

\section{General informed consent}

General informed consent was documented with a consent form signed and dated by both the subject or the subject's legal representative and the person conducting the consent discussion. A copy of the signed and dated consent form was given to the subject before their participation in the study. Informed consent adheres to institutional review board/ethics review committee (IRB/ERC) requirements, applicable laws and regulations, and Sponsor requirements.

\section{Statistical analysis}

All statistical analysis was performed using Statistical Package for the Social Sciences (SPSS) version 17.0 for Windows (SPSS, Chicago, IL). The statistical methods used for the requirements of the study were tests of the statistical significance of differences between proportions and Student's t-test. According to the power analysis, each subsample should have at least 21 physicians and 80 patients to have sufficient power (0.9) for the desired effect size and significance level (0.05). The study was designed to have $90 \%$ power to detect a difference of 5\%. A $p$-value of 0.05 was considered statistically significant. Although the patients were recruited using a two-step procedure, the recruiting physician was not used as a random factor in the analysis The preliminary variance components analysis showed that the recruiting site does not have a significant impact on primary outcome (HbAlc level), showing no significance for either recruiting physician or the interaction with country or $\mathrm{GP} /$ specialist. This is probably due to both the relatively low number of patients per doctor [10] and the fact that the patients are not necessarily treated by the recruiting doctor.

\section{Results}

\section{Patient baseline characteristics}

All patients were adults between 20 and 92 years of age (average age $63.5 \pm 10.7$ years). They had been diagnosed with type 2 DM for 1-61 years (average $8.9 \pm 7.1$ years) and $51 \%$ were male. Of the patients $35 \%$ had achieved the target HbAlc value of $<6.5 \%(48 \mathrm{mmol} / \mathrm{mol})$, while $33 \%$ had HbAlc levels $>7.5 \%$ (58 mmol/mol). Measurement of HbAlc was found to be quite infrequent, with only $40 \%$ of patients having their hemoglobin measured at least every 6 months and as many as 34\% less than every 12 months or never (Fig. 1).

\section{Glycemic control}

The results of the present study showed that the level of glycemic control in the region was poor, with an average $\mathrm{HbAlc}$ level of $7.3 \% \pm 1.5(56 \mathrm{mmol} / \mathrm{mol})$. The difference between the proportion of well-controlled patients was not statistically significant between doctors who do and do not have access to HbAlc measurement, nor were they statistically significant between GPs and specialists ( $p=0.87$ and 0.099 , respec- 
Fig. 1 Relationship between $\mathrm{HbA} 1 \mathrm{c}$ testing intervals and point of care

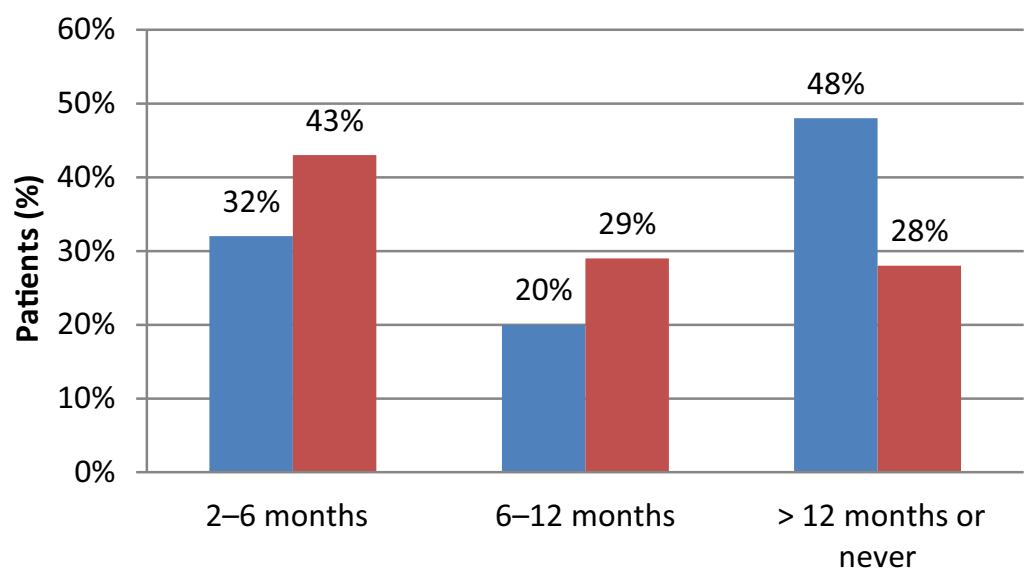

Intervals between requests for testing

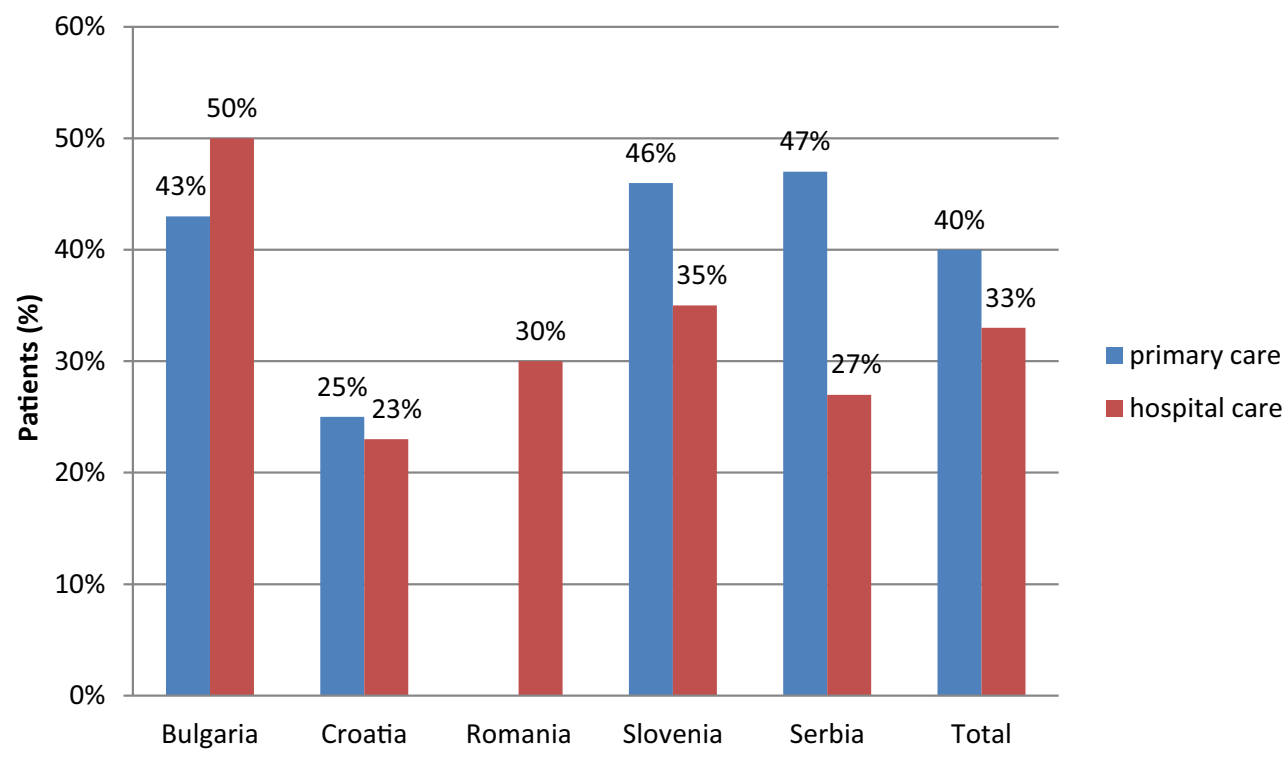

Fig. 2 Patients who have achieved adequate glycemic control $(\mathrm{HbA} 1 \mathrm{c}<$ $6.5 \%)$ tively). The difference between the proportion of wellcontrolled patients of doctors who measured HbAlc often and of those who do not was not statistically significant either $(p>0.05)$.

\section{HbA1c measurement}

It is important to note that the proportion of patients with adequate glycemic control ranged from 23-50\% (Fig. 2). It was significantly lower in Croatia, as compared with Serbia, Slovenia, and Bulgaria, and was significantly higher in Bulgaria than any other Balkan country except for Serbia, where the difference is not statistically significant. The proportion of patients with adequate glycemic control was significantly lower in patients of specialists across the entire sample $(p=0.016)$. These differences are not significant for Bulgaria, Croatia, or Serbia ( $p=0.4,0.6$ and 0.2 , respectively) but are significant for Slovenia $(p=0.001)$.

\section{Frequency of measurement}

The frequency of measurement was also found to be higher in patients regularly monitored by specialists ( $43 \%$ vs. $32 \%$ of patients monitored at least every 6 months, $p<0.01$ ) (Figs. 1, 3 and 4).

\section{Diabetes therapy}

The most frequent therapy was shown to be metformin monotherapy (28\% of patients), followed by a combination of metformin and sulphonylurea (23\%) regardless of a low level of disease control in those patients (Fig. 5). Furthermore, adequate disease control was achieved in $55 \%$ of patients undergoing metformin monotherapy and in 32\% undergoing combined therapy.

Patients treated with metformin had established better disease control; however, $40 \%$ of them still showed no improvement. Insulin was also quite prevalent, and was the only drug prescribed almost 
Fig. 3 Relationship between availability of point-of-care HbA1c testing device and adequate glycemic control achievement $(\mathrm{HbA} 1 \mathrm{c}<6.5 \%)$

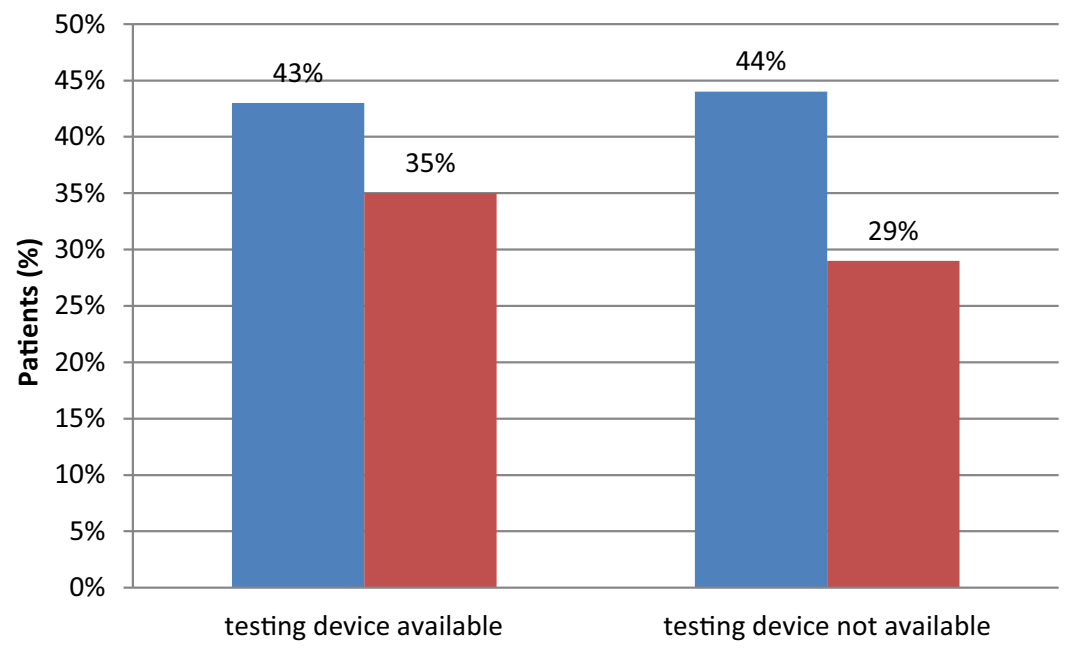

primary care

hospital care

Fig. 4 Relationship between $\mathrm{HbA} 1 c$ testing interval and adequate glycemic control achievement $(\mathrm{HbA} 1 \mathrm{c}<$ $6.5 \%)$

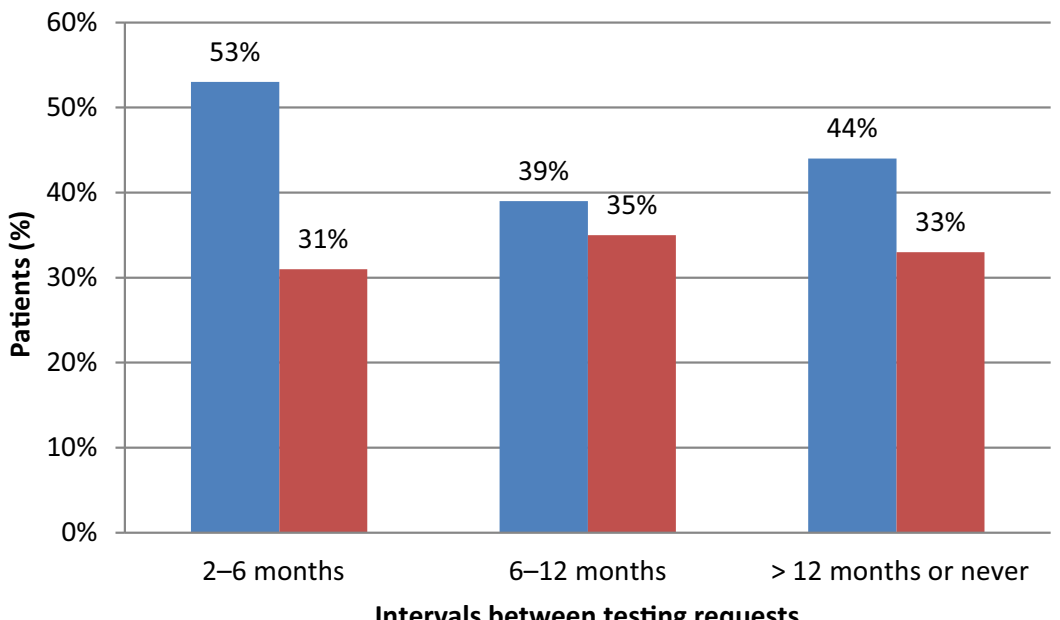

primary care

hospital care

Intervals between testing requests

exclusively by specialists; however, patients on insulin were very poorly controlled. The difference between metformin and insulin prescription was statistically significant between GPs and specialists ( $p=0.007$ and $p<0.001$, respectively). The use of the drug showed a similar general pattern across the countries in both subsamples.

\section{Changes in therapy and interventions}

Measurement of HbAlc in physician's offices resulted in only a small percentage of therapy changes or interventions in patients with an HbAlc level $\geq 6.5 \%$ $(48 \mathrm{mmol} / \mathrm{mol})$; therapy was unchanged in $91 \%$ of cases, stepped up in only $7.2 \%$ of cases, adding sulphonylurea to metformin, prescribing a dipeptidyl peptidase-4 (DPP-4) inhibitor, introducing insulin or other drugs (Figs. 6 and 7). Another interesting fact noted was that therapy was stepped down for $2 \%$ of patients by switching from combined metformin and sulphonylurea therapy to monotherapy (Fig. 6). Finally, doctors were mostly not surprised $(79 \%)$ or were pleasantly surprised $(11 \%)$ by the patients HbAlc results and $53 \%$ of doctors stated that they would monitor HbAlc more frequently in the future.

A stepwise multivariate regression across patient characteristics (age, time since diagnosis, treated by GP or specialist) and manner of disease monitoring (measuring blood glucose using glucometer at home or measuring HbAlc) and frequency of measurement (number of blood glucose measurements or time since last HbAlc measurement) yielded a statistically significant model with the major predictor variable impact of type-2 DM time since diagnosis (significance $<0.001$, predictor importance 0.608 ) and the use of blood glucose as a measurement tool (significance $<0.001$, predictor importance 0.240 ). The usage and the frequency of HbAlc measurement was not shown to significantly influence DM control in the region.

\section{Discussion}

People with Type 2 DM can remain undiagnosed for many years, unaware of the long-term damage caused by the disease. The struggle for tight glycemic control results in large blood glucose fluctuations over time. 
Fig. 5 Initial diabetes therapy (Met metformin, DPP$4 i$ dipeptidyl peptidase-4 inhibitor, $D P P-4 i+$ Met dipeptidyl peptidase-4 inhibitor + metformin, GLP-1 glucagonlike peptide-1 receptor agonists)

Fig. 6 Therapeutic intervention approach in patients with inadequate glucose control (SU sulphonylurea, $D P P-4 i$ dipeptidyl peptidase-4 inhibitor)

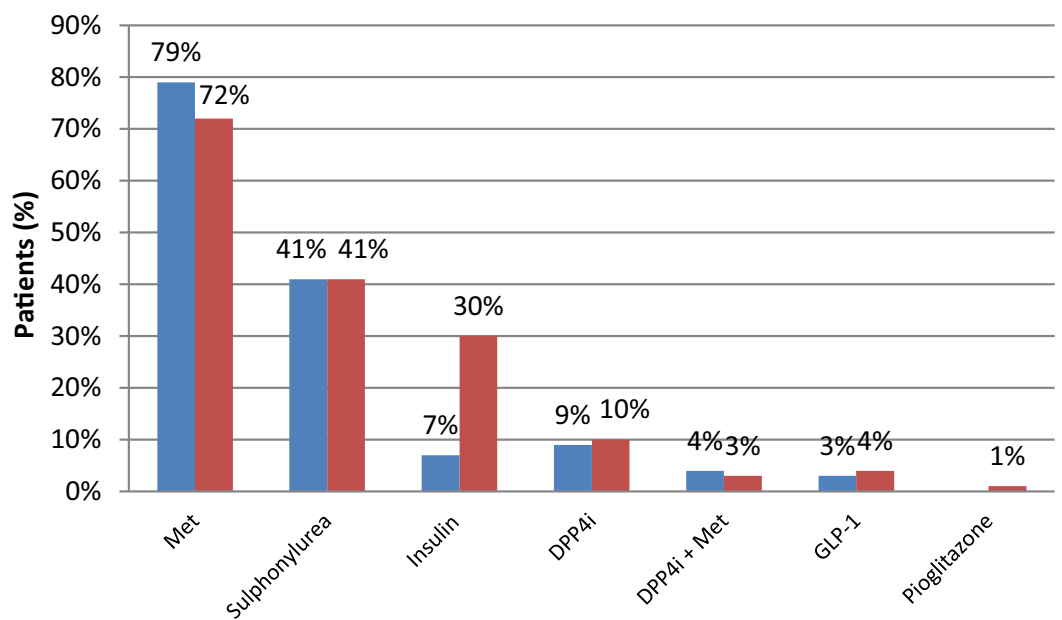

primary care

hospital care

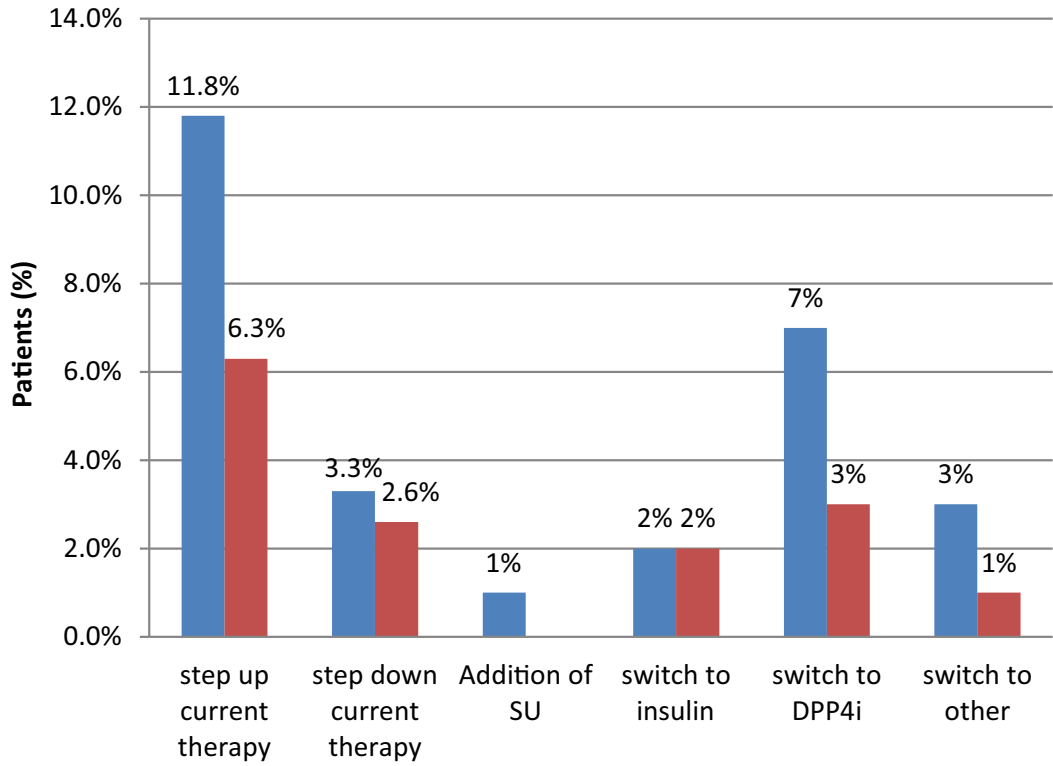

primary care

hospital care
These fluctuations are the measurable result of the action of a complex dynamic system that is influenced by many internal and external factors, including the timing and amount of insulin and other drug therapies, diet, physical activity. [19].

\section{Routine HbA1c measurement}

The level of HbAlc provides a reliable measure of chronic glycemic control without the need for a fasting or timed sample. Routine measurement of HbAlc has remained the standard biomarker and the gold standard for monitoring glycemic control in patients with diabetes [8, 19]. Evidence shows that having an HbAlc result at the time of a doctor's visit is beneficial [11]. According to previous studies HbAlc is also a practical and convenient tool for screening undiagnosed diabetes in a routine health check-up [7, 20-22, 27].
The rate of routine measurements of $\mathrm{HbAlc}$ in Type 2 DM patient care in the Balkans is uncertain. The results of a study performed in Croatia in 2011 implied poor glycemic control [16]. The level of glycemic control in patients is unknown both in Croatia and in other Balkan countries. According to the results of the study, measurement of HbAlc is generally quite low, especially in GP patients, and is lower than $50 \%$ in all countries. Specialists measure HbAlc more often in Croatia and Serbia, while in Slovenia and Bulgaria they measure it just as rarely as GPs. In general $50 \%$ of GP patients and $41 \%$ of specialist patients did not have HbAlc measurements taken in over 1 year. Significantly, if the patient is seen more frequently by a specialist, it is more likely that a current HbAlc measurement is available. A higher frequency of measurement by specialists is likely due to better access to measurement in hospitals and specialists' higher level of education.; however, not even specialists seem to measure HbAlc for all pa- 
Fig. 7 Relationship between therapeutic intervention approach by stepping up or stepping down therapy and $\mathrm{HbA} 1 \mathrm{c}$ measure at follow-up visit

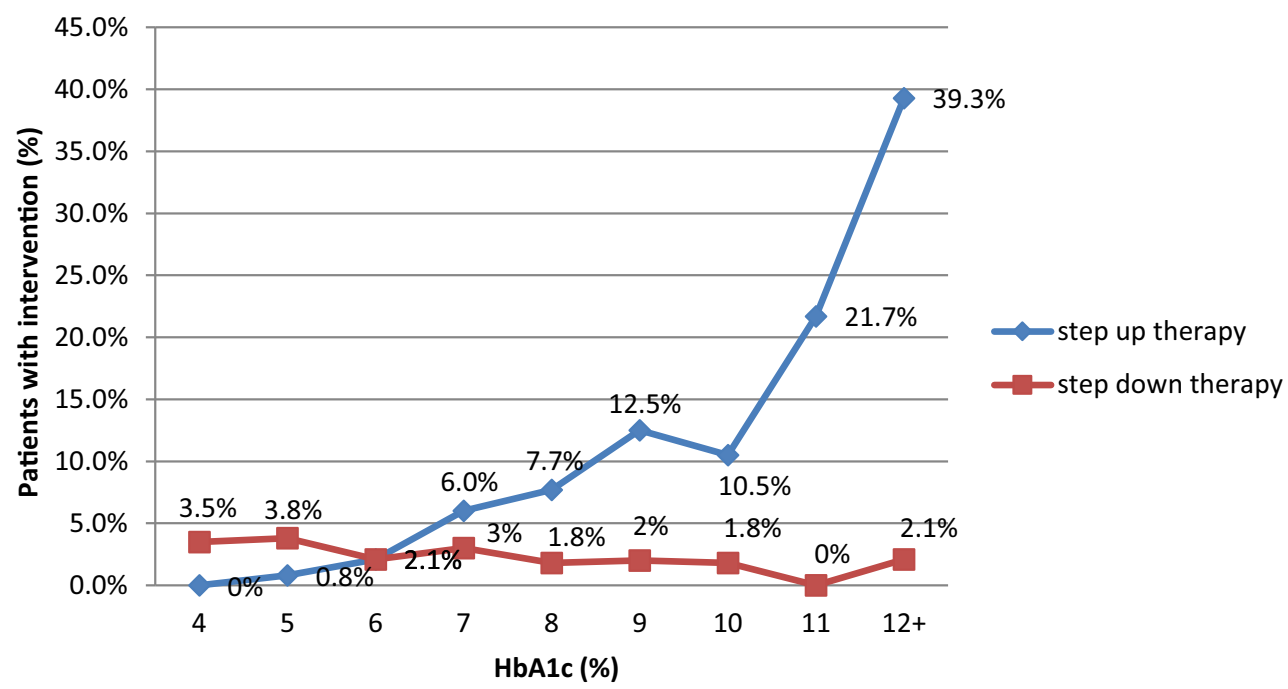

tients. The significantly lower proportion of patients at specialists with adequate glycemic control can be explained by the referral of more difficult patients from GPs to specialists for therapy modification and more strictly controlled treatment. Existing data show that real-time HbAlc estimation could increase patient motivation to improve diabetes control [19].

\section{Cut-off value}

Although the results of HbAlc measurement in this study were poor (only $35 \%$ of patients had HbAlc < $6.5 \%)$, less strict thresholds would only moderately increase the proportion of well-controlled patients but still leave a considerable proportion poorly controlled, regardless of the criteria used. It is incumbent on the clinician to know when HbAlc results should be questioned, such as when the value is discordant from the patient's self-monitoring blood glucose values, or when there has been an acute change in glycemia, such as recent treatment with glucocorticoids [8].

\section{Therapy}

Patients on metformin were better controlled but more than $40 \%$ were not. Noticeably, patients on insulin were very poorly controlled, implying the late introduction of insulin; however, it was noticed that therapy was stepped up only for a small number of patients $(5-7 \%)$.

\section{Self-management}

Self-management is achievable through adherence to professional advice regarding diet, exercise, and medication. The effectiveness of structured self-monitored blood glucose testing has an empowerment effect on the patient and results in better metabolic control in people with type $2 \mathrm{DM}$ [23]. The more active participation of patients in self-care management pro- duces better metabolic outcomes and better compliance with treatment protocols [23]. A study performed in the Balkans included only adult patients. A study on elderly type $2 \mathrm{DM}$ patients showed that $\mathrm{HbAlc}$ is a relevant tool for assessing patient glycemic control and adherence [24]. Complimentarily, HbAlc measured at gestational DM (GDM) diagnosis may be a useful tool for identifying GDM patients at highest risk of developing postpartum abnormal glucose [25]. Considering the fact that weight-related problems are on the rise in many populations worldwide, diabetes experts are still leading the battle against DM. The progression of diabetes can also be delayed by intensive intervention [26].

\section{Study strengths and limitations}

The strengths of the study are the comprehensive approach to its design as an observational, noninterventional, and cross-sectional study, the highly-structured protocol, and the set of statistical analyses to determine the effects of protocol completion. There were no major limitations to this study. The lack of a control is a minor limitation of this observational study; however, the design is appropriate for the intended purpose of the study.

\section{Conclusion}

Type $2 \mathrm{DM}$ is a noteworthy preventable disease and an increasing public health problem [26]. Effective management requires partnership between diabetes patients and health professionals. The appropriate use of structured self-monitoring of blood glucose significantly improves glycemic control and facilitates adherence to recommendations about nutrition and physical activity as well as more timely and aggressive treatment changes without decreasing general wellbeing [28]. 
The main finding of this study is that the provision of an easy to use and cost-free HbAlc measurement device does not positively influence treatment patterns of patients with type $2 \mathrm{DM}$ in the Balkans. In this age of modern technology, online monitoring, and available testing it is unacceptable that less than $50 \%$ of diabetes patients are well-controlled. Emerging technologies have created continuous glucose monitoring systems that allow frequent, real time glucose measurements, which may possibly be superior to oral glucose tolerance test (OGTT) and HbAlc measurement [29]. The move towards HbAlcbased diagnosis has obviously generated controversy. Unfortunately, diabetes is still not under control in the Balkans. More studies are necessary to explore the reasons for this phenomenon. The usage and frequency of HbAlc measurement was not shown to significantly influence DM control in the region. Nevertheless, the results that this study has produced show that HbAlc measurement should be performed strictly according to the guidelines.

Acknowledgements The authors would like to express their gratitude to all participating clinicians, investigators, and patients for their assistance and commitment to this research effort. The manuscript was written by an independent medical writer who had full and independent access to all study data and was independently responsible for the development, writing, and overview of the entire manuscript. All authors have read and approved the final manuscript. Kudikamo d.o.o. performed the statistical analysis. Merck Sharp \& Dohme d.o.o. and Altiora d.o.o. designed and performed the study, collected and researched the data, and developed the manuscript.

Funding Funding for this research was provided by Merck Sharp \& Dohme d.o.o., Zagreb, Croatia; Merck Sharp \& Dohme, Bucharest, Romania; Merck Sharp \& Dohme, Sofia, Bulgaria; MSD Idea, Inc., Belgrade, Serbia; Merck Sharp \& Dohme, inovativna zdravila d.o.o., Ljubljana, Slovenia. Participating physicians were funded for their enrollment of patients.

Conflict of interest M. Cokolic, N.M. Lalic, D. Micic, G. Mirosevic, S. Klobucar Majanovic, I.N. Lefterov, and M. Graur declare that they have no competing interests.

Open Access This article is distributed under the terms of the Creative Commons Attribution 4.0 International License (http://creativecommons.org/licenses/by/4.0/), which permits unrestricted use, distribution, and reproduction in any medium, provided you give appropriate credit to the original author(s) and the source, provide a link to the Creative Commons license, and indicate if changes were made.

\section{References}

1. IDF. Diabetes Atlas, 6th edition 2013. http:// www.diabetesatlas.org/component/attachments/? task=download\&id=76. Accessed 5 December 2016.

2. IDF. Diabetes Atlas, 5th edition 2011. http:// www.diabetesatlas.org/component/attachments/? task=download\&id=70. Accessed 5 December 2016 .

3. World Health Organization. Definition and diagnosis of diabetes mellitus and intermediate hyperglycemia: report of a WHO/IDF consultation 2006. http://www.who.int/ diabetes/publications/Definition\%20and\%20diagnosis \%20of\%20diabetes_new.pdf. Accessed 22 March 2015.

4. UK Prospective Diabetes Study (UKPDS) Group. Intensive blood-glucose control with sulphonylureas or insulin compared with conventional treatment and risk of complications in patients with type 2 diabetes (UKPDS33). Lancet. 1998;352(9131):837-53.

5. The Diabetes Control and Complications Trial Research Group. The effect of intensive treatment of diabetes on the development and progression of long-term complications in insulin-dependent diabetes mellitus. N Engl J Med. 1993;329:997-986.

6. Degeling C, Rock M. Haemoglobin Alc as a diagnostic tool: public health implications from an actor-network perspective. Am J Public Health. 2012;102(1):99-106.

7. Li LJ, Zhou JX, Chen HT, Song YL, Xue YM. Effect of HbAlc combined FPG on screening diabetes in health check-up. Asian Pac J Trop Med. 2012;5(6):472-5.

8. Radin MS. Pitfalls in hemoglobin Alc measurement: when results may be misleading. J Gen Intern Med. 2014;29(2):388-94.

9. American Diabetes Association. Standards of medical care in diabetes 2012. Diabetes Care. 2012;35:S11-S63.

10. Cagliero E, Levinia EV, Nathan DM. Immediate feedback of HbAlc levels improves glycemic control in type 1 and insulin treated type 2 diabetic patients. Diabetes Care. 1999;22(11):1785-9.

11. Nathan DM, Buse JB, et al. Medical management of hyperglycemia in type 2 diabetes: a consensus algorithm for the initiation and adjustment of therapy. A consensus of the American Diabetes Association and the European Association for the Study of Diabetes. Clin Diabetes. 2009;27(1):4-16.

12. Miller CD, Barnes CS, Phillips LS, Ziemer DC, Gallina DL, Cook CB, et al. Rapid Alc availability improves clinical decision-making in an urban primary care clinic. Diabetes Care. 2003;26(4):1158-63.

13. Kokić S, Prašek M, Pavlic Renar I, Rahelic D, Pavic E, Jandric Balen M, et al. Hrvatske smjernice za liječenje šećerne bolestitipa 2. Medix. 2011;2:8-34.

14. Lalić NM, Zamaklar M, Pantelinac P, Zdravković D, Bajović Lj, Kostić N. et al. Diabetes Mellitus. Nacionalni komitet za izradu Vodiča kliničke prakse u Srbiji, Radna grupa za dijabetes. Beograd: Grafika Jovšić; 2002. VI:122.

15. Bulgarian Society of Endocrinology, Borissova AM. Metodičniukazaniipozaharendiabet. Sofia: Rumen Ninov; 2008. http://endo-bg.com/. Accessed5 December 2016.

16. GfkDatascan Market Research Study 2011, Data on file, MSD d.o.o. Zagreb, Croatia.

17. Medvešček M, Mrevlje F. Slovene Diabetic Society, Endocrinology clinic, Internal clinic, University of Ljubljana: Slovenske smernice za klinično obravnavo sladkorne bolezni tipa 2 pri odraslih osebah 2011. http://www. endodiab.si. Accessed 22 March 2015.

18. Siemens Healthineers. DCA Vantage ${ }^{\mathrm{TM}}$ analyzer-technical specifications 2015. http:/ /www.healthcare.siemens.com/ point-of-care/diabetes/dca-vantage-analyzer/technicalspecifications. Accessed 22 March 2015.

19. Kovatchev BP, Flacke F, Sieber J, Breton MD. Accuracy and robustness of dynamical tracking of average glycemia (Alc) to provide real-time estimation of hemoglobin Alc using routine self-monitored blood glucose data. Diabetes Technol Ther. 2014;16(5):303-9.

20. Exebio JC, Zarini GG, Vaccaro JA, Exebio C, Huffman FG. Use of hemoglobin AlC to detect Haitian-Americans with 
undiagnosed Type 2 diabetes. Arq BrasEndocrinol Metabol. 2012;56(7):449-55.

21. Choi SH, Kim TH, Lim S, Park KS, Jang HC, Cho NH. Hemoglobin Alc as a diagnostic tool for diabetes screening and new-onset diabetes prediction: a 6 -year communitybased prospective study. Diabetes Care. 2011;34(4):944-9.

22. Nowicka P, Santoro N, Liu H, Lartaud D, Shaw MM, Goldberg R, Guandalini C, Savoye M, Rose P, Caprio S. Utility of hemoglobin A(1c) for diagnosing prediabetes and diabetes in obese children and adolescents. Diabetes Care. 2011;34(6):1306-11.

23. Khamseh ME, Ansari M, Malek M, Shafiee G, Baradaran $H$. Effects of a structured self-monitoring of blood glucose method on patient self-management behavior and metabolic outcomes in type 2 diabetes mellitus. J Diabetes Sci Technol. 2011;5(2):388-93.

24. Manan MM, Husin AR, Alkhoshaiban AS, Al-Worafi YM, Ming LC. Interplay between oral hypoglycemic medication adherence and quality of life among elderly type 2 diabetes mellitus patients. JClin Diagn Res. 2014;8(12):JC05-JC09.

25. Katon J, Reiber G, Williams MA, Yanez D, Miller E. Hemoglobin Alc and postpartum abnormal glucose toleranceamongwomenwith gestational diabetes mellitus. Obstet Gynecol. 2012;119(3):566-74.
26. Costa B, Barrio F, Piñol JL, Cabré JJ, Mundet X, Sagarra R, et al. DE-PLAN-CAT/PREDICEResearch Group. Shifting from glucose diagnosis to the new HbAlc diagnosis reduces the capability of the Finnish Diabetes Risk Score (FINDRISC) to screen for glucose abnormalities within a real-life primary healthcare preventive strategy. BMCMed. 2013;11:45.

27. Muktabhant B, Sanchaisuriya P, Sarakarn P, Tawityanon W, Trakulwong M, Worawat S, Schelp FP. Use of glucometer and fasting blood glucose as screening tools for diabetes mellitus type 2 and glycated haemoglobin as clinical reference in rural community primary care settings of a middleincome country. BMC Public Health. 2012;12:349.

28. Polonsky WH, Fisher L, Schikman CH, Hinnen DA, Parkin CG, Jelsovsky Z, et al. Structured self-monitoring of blood glucose significantly reduces A1C levels in poorly controlled, noninsulin-treated type 2 diabetes: results from the Structured Testing Program study. Diabetes Care. 2011;34(2):262-7.

29. Soliman A, DeSanctis V, Yassin M, Elalaily R, Eldarsy NE. Continuous glucose monitoring system and new era of early diagnosis of diabetes in high risk groups. Indian J Endocrinol Metab. 2014;18(3):274-82. 